\title{
Knowledge and Practices of Periodontal Health and Oral Hygiene among BDS Students
}

\author{
Dr. Suprim Malla, ${ }^{1}$ Dr. Reshma Shrestha, ${ }^{2}$ Dr. Bhageshwar Dhami, ${ }^{3}$ Dr. Sujaya Gupta, ${ }^{3}$ Dr. Satish Deo ${ }^{4}$ \\ ${ }^{1}$ Dental Surgeon, City Dental Clinic, Kathmandu, Nepal, ${ }^{2}$ Dental Surgeon, All Smile Dental Clinic, Kathmandu, Nepal, \\ ${ }^{3}$ Department of Periodontics, Kantipur Dental College, Kathmandu, Nepal, \\ ${ }^{4}$ Department of Clinical Pharmacology, Institute of Medicine, Maharajgunj, Kathmandu, Nepal.
}

\begin{abstract}
Background: Periodontal disease is an inflammatory oral disease that affects the soft and hard tissues supporting the teeth. Gingivitis, an early stage, when untreated leads to periodontitis that causes progressive tooth mobility leading towards tooth loss. Periodontitis is ubiquitous and commonly manifests in adult life. Early detection of oral diseases makes them more amenable to treatment and allows better chance of cure. BDS students are young adults who are going to be future oral health care provider. Their knowledge and oral hygiene practices may impact oral health status of a society.
\end{abstract}

Aims: The aim of this study was to evaluate the knowledge of oral health and periodontal disease and correlate it with oral hygiene practices among BDS students not exposed to clinical practice.

Materials and Methods: This cross-sectional study was carried out among 120 students of first, second and third year BDS at Kantipur Dental College. The students who were not exposed to clinical practice were invited to participate. The data was collected by self-administered structured questionnaire. There were total of 15 questions on knowledge and oral hygiene practice and scores were assigned to each question. Data analysis was done by SPSS 20 software program.

Results: The mean knowledge score of the population was $6.58 \pm 1.29$ and mean practice score as $6.20 \pm 1.73$. The participants had good knowledge (55\%) of oral health and periodontal diseases. However, only $22.5 \%$ of participants followed good oral hygiene practices. There was no significant difference of knowledge between males and females $(p=0.831)$ but a statistically significant difference was seen in the practice of oral hygiene $(p=0.006)$.

Conclusion: Despite having good knowledge (55\%) of oral and periodontal health, $77.5 \%$ of the BDS students did not follow good oral hygiene practices on a regular basis. Dental students must be encouraged to be good role models in practicing as well as promoting oral health. The authors would like to recommend incorporating some oral health and preventive dentistry topics in the non-clinical BDS curriculum.

Keywords: knowledge; oral health; oral hygiene; periodontal health; practice; tooth brushing.

\section{INTRODUCTION}

Periodontal diseases are one of the most common diseases among population and, when left untreated, lead to tooth loss. ${ }^{1}$ Staggering $47.5 \%$ of Nepalese population suffer from periodontitis. ${ }^{2}$ Periodontitis has been associated with many systemic conditions such as cardiovascular diseases, diabetes, preterm low birth weight deliveries, rheumatoid arthritis, pulmonary diseases, etc. Thus, maintaining good oral health is important not only for healthy dental status but also for improved systemic health. ${ }^{3}$ The main cause

\author{
Correspondence: \\ Dr. Sujaya Gupta \\ Kantipur Dental College, Kathmandu, Nepal. \\ email: sujayaagupta@gmail.com \\ Citation
}

Malla S, Shrestha R, Dhami B, Gupta S, Deo S. Knowledge and practices of periodontal health and oral hygiene among BDS students. J Nepal Soc Perio Oral Implantol. 2017;1(2):51-4. of periodontal disease is bacterial plaque although many other factors such as smoking, diabetes, drugs, stress, haematological disorders and hormonal changes, may affect the initiation and progression of gingival and periodontal diseases. ${ }^{4}$ Taking care of oral hygiene by removing dental plaque remains mainstay of maintaining oral and periodontal health. The young adult age group can be motivated to instil good oral hygiene practices at an early age for life-long good oral health conditions.

The Bachelor of Dental Surgery (BDS) students, who are not exposed to the clinical practice and the subject of Periodontology in their curriculum, are good representative of health aware individuals of the young adult age group.

This study was conducted to evaluate the knowledge of periodontal health and various oral hygiene practices among BDS students and to assess the potential relationship among gender, level of knowledge and practices of oral hygiene. 


\section{MATERIALS AND METHODS}

This is a cross-sectional observational study, carried out among 120 students of Kantipur Dental College, Kathmandu, Nepal during May 2017. Before embarking upon the study, proposal was submitted to ethical committee and approval was taken. The students who were not exposed to clinical practice were recruited for the study. Utmost confidentiality was maintained and no names, documents are disclosed anywhere other than among the researchers. The inclusion criteria included students of first, second and third year enrolled in BDS program and willing to sign an informed consent. The exclusion criteria included the students who had attended lectures of Periodontics or exposed to clinical practice.

Convenience sampling method was utilized and the sample size of 114 was calculated using Slovin's (1960) formula:

$$
\mathrm{n}=\frac{\mathrm{N}}{1+\mathrm{Ne}^{2}}=113.16
$$

Where $\mathrm{n}=$ required sample size

$\mathrm{N}=$ population size $=126$

$\mathrm{e}=$ margin of error $=0.03$ (at confidence level 99\%)

$1=$ constant value

The participants completed a self-administered structured questionnaire. The questionnaire consisted of items to assess participants' personal data (age, gender) and knowledge related to periodontal health and their oral hygiene practices. There were total nine questions on knowledge with maximum score nine (Table 1) and six questions on oral hygiene practice with maximum score of 10 (Table 2).

The data from the proforma were entered in Microsoft Excel and statistical analyses were performed using Statistical Package for Social Sciences (SPSS) software program version 20.0.Chicago: SPSS IBM Corp. The scores of knowledge and oral hygiene practice were graded as Good, Fair and Poor (Table 3). Statistical significance was based on probability values of less than 0.05. Potential association among knowledge of periodontal health, oral hygiene practices and gender were analysed (Table 3).

\section{RESULTS}

The minimum knowledge score of the population was observed to be three and maximum nine while the minimum practice score was two and maximum 10. The mean knowledge score of the population was found to be $6.58 \pm 1.29$ and mean practice score as $6.20 \pm 1.73$ (Table 3).

When the knowledge scores were checked with gender there was no significant difference $(p=0.0831)$ while the practice scores showed a statistically significant ( $p=0.006$ ) association (Table 3).

The age of the participants ranged from 20 to 24 years $(21.26 \pm 0.95)$ and among all the participants (120) there were 27 (22.5\%) males and 93 (77.5\%) females (Table 3).

Table 1: Knowledge of periodontal health and oral hygiene (total score $=9$ ).

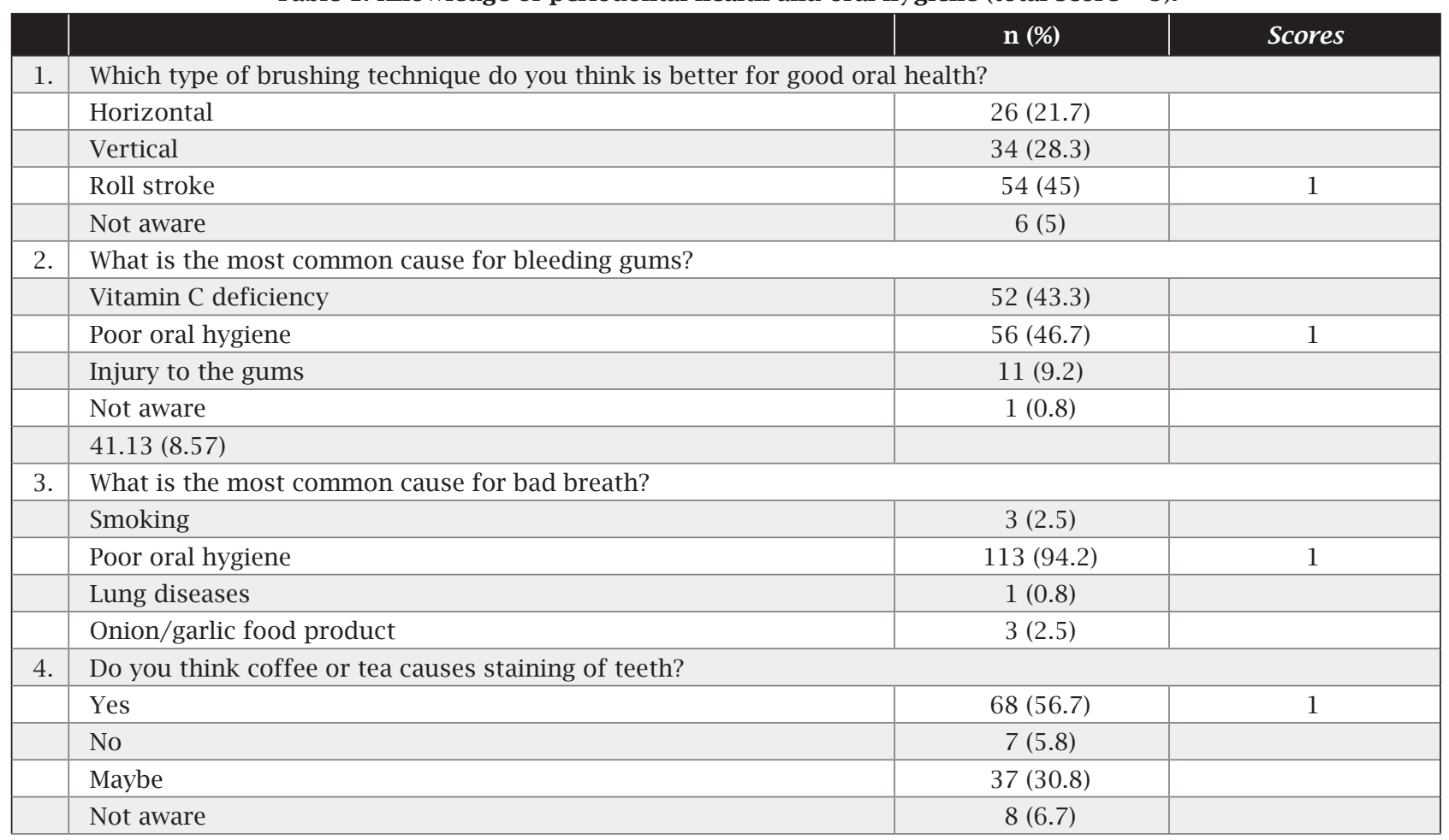




\begin{tabular}{|c|c|c|c|}
\hline \multirow[t]{2}{*}{5.} & \multicolumn{3}{|c|}{ What do you think is the most common cause for loose teeth? } \\
\hline & Old age & $39(32.5)$ & \\
\hline & Diabetes & $1(0.8)$ & \\
\hline & Poor oral hygiene & $74(61.7)$ & 1 \\
\hline & Accident/ Injury & $6(5)$ & \\
\hline \multirow[t]{5}{*}{6.} & \multicolumn{3}{|c|}{ Do you think sensitivity to hot or cold food can be treated? } \\
\hline & Yes & $95(79.2)$ & 1 \\
\hline & No & $8(6.7)$ & \\
\hline & Maybe & $14(11.7)$ & \\
\hline & Not aware & $3(2.5)$ & \\
\hline \multirow[t]{5}{*}{7.} & \multicolumn{3}{|c|}{ Do you think bad oral hygiene affects your general health? } \\
\hline & Yes & $115(95.8)$ & 1 \\
\hline & No & $1(0.8)$ & \\
\hline & Maybe & $3(2.5)$ & \\
\hline & Not aware & $1(0.8)$ & \\
\hline \multirow[t]{5}{*}{8.} & \multicolumn{3}{|c|}{ What is the most common cause for receding gums? } \\
\hline & Improper tooth brushing & $109(90.8)$ & 1 \\
\hline & Nail biting habit & $4(3.3)$ & \\
\hline & Injury & $4(3.3)$ & \\
\hline & Diabetes & $3(2.5)$ & \\
\hline \multirow[t]{5}{*}{9.} & \multicolumn{3}{|c|}{ Has any member of your family lost more than 6 teeth at young age of $<35$ years? } \\
\hline & Yes & $4(3.3)$ & 1 \\
\hline & No & $101(84.2)$ & 1 \\
\hline & Maybe & $4(3.3)$ & \\
\hline & Not aware & $11(9.2)$ & \\
\hline
\end{tabular}

Table 2: Practices of oral hygiene (total score $=10$ ).

\begin{tabular}{|c|c|c|c|}
\hline & & n (\%) & Scores \\
\hline 1. & \multicolumn{3}{|l|}{ Do you brush your teeth daily? } \\
\hline & Yes & 119 (99.2) & 1 \\
\hline & No & $1(0.8)$ & \\
\hline 2. & \multicolumn{3}{|l|}{ How often do you brush your teeth? } \\
\hline & Once daily regularly & $44(36.7)$ & 1 \\
\hline & Twice daily regularly & $76(63.3)$ & 1 \\
\hline & Once daily irregularly & - & \\
\hline & Sometimes & - & \\
\hline 3. & \multicolumn{3}{|l|}{ How often do you change your toothbrush? } \\
\hline & 6 months & $24(20)$ & 1 \\
\hline & 3 months & $92(76.7)$ & 2 \\
\hline & 1 year & $3(2.5)$ & \\
\hline & Till bristles get frayed & $1(0.8)$ & \\
\hline 4. & \multicolumn{3}{|l|}{ Do you use dental floss regularly? } \\
\hline & Sometimes & $49(40.8)$ & 1 \\
\hline & Yes & $11(9.2)$ & 2 \\
\hline & No, I am not aware of it & $60(50)$ & \\
\hline \multirow[t]{5}{*}{5.} & \multicolumn{3}{|l|}{ How often do you use mouthwash? } \\
\hline & Never & $56(46.7)$ & \\
\hline & Once in a week & $15(12.5)$ & 1 \\
\hline & Once a day for two weeks & $3(2.5)$ & 1 \\
\hline & As prescribed by the dentist & $46(38.3)$ & 2 \\
\hline \multirow[t]{5}{*}{6.} & How often you visit your dentist for dental check-up? & & \\
\hline & In 3 months & $7(5.8)$ & 1 \\
\hline & In 6 months & $34(28.3)$ & 2 \\
\hline & Once in a year & $41(34.2)$ & 1 \\
\hline & Never visit & $38(31.7)$ & \\
\hline
\end{tabular}


Table 3: Gender correlation with knowledge and practice scores.

\begin{tabular}{|c|c|c|c|c|c|c|c|}
\hline & Good n (\%) & Fair n (\%) & Poor n (\%) & Total n (\%) & p value & Mean \pm S.D. & Mode \\
\hline Knowledge scores & 7 to 9 & 5 to 6 & $\leq 4$ & & & & \\
\hline Male & $16(13.3)$ & $9(7.5)$ & $2(1.7)$ & $27(22.5)$ & \multirow{3}{*}{0.831} & \multirow{3}{*}{$6.58 \pm 1.29$} & \multirow{3}{*}{7} \\
\hline Female & $50(41.7)$ & $37(30.8)$ & $6(5)$ & $93(77.5)$ & & & \\
\hline Total & $66(55)$ & $46(38.3)$ & $8(6.7)$ & $120(100)$ & & & \\
\hline Practice scores & 8 to 10 & 5 to 7 & $\leq 4$ & & & & \\
\hline Male & $7(5.8)$ & $9(7.5)$ & $11(9.2)$ & $27(22.5)$ & \multirow{3}{*}{0.006} & \multirow{3}{*}{$6.20 \pm 1.73$} & \multirow{3}{*}{7} \\
\hline Female & $20(16.7)$ & $59(49.2)$ & $14(11.7$ & $93(77.5)$ & & & \\
\hline Total & $27(22.5)$ & $68(56.7)$ & $25(20.8)$ & $120(100)$ & & & \\
\hline
\end{tabular}

\section{DISCUSSION}

Periodontal health is essential component of oral health and its significance for systemic health and general well-being has been emphasized time and again. ${ }^{5}$ To achieve good oral as well as periodontal health, toothbrush and oral hygiene aids should be used regularly on a daily basis and in correct manner. Early detection of oral diseases makes them more amenable to treatment and allows better chance of cure. ${ }^{6}$ Dental plaque should be removed at least every 48 hours for good periodontal health.

Dental students are the young adults and future oral health care providers. Their self-awareness regarding periodontal health is vital. ${ }^{7}$ Their knowledge and oral hygiene practices can be useful in promoting the importance of oral and periodontal health for systemic health and general wellbeing. Periodontal diseases can be prevented by proper tooth brushing, use of interdental aids, dental flossing and timely visits to dentist. ${ }^{7}$

Periodontal health knowledge was good (55\%) among the BDS students which is in accordance with studies done by Andhare et al. ${ }^{7}$ It could be attributed to in part to their increased interest as part of their professional education.

However, only $22.5 \%$ of the participants followed good oral hygiene practices. It could be because of lack of exposure to clinical environment. ${ }^{8}$
Female students did not show difference in knowledge of periodontal health which differs from the studies of Ahamed et al., ${ }^{8}$ Sharda et al. ${ }^{9}$ However, it agrees with authors in that oral hygiene practice scores were better in females, similar to Al-Omari et al. ${ }^{10}$

The limitation of this study was that it was an observational study for a short period in only one dental college. A comparative study with BDS students exposed to clinical setting8 including other dental colleges as well or compared to non-dental undergraduate students ${ }^{7}$ would have given broader glimpse of actual scenario of knowledge and oral hygiene practice in the young adult age group.

\section{CONCLUSION}

Despite having good knowledge (55\%) of oral and periodontal health, $77.5 \%$ of the BDS students did not follow good oral hygiene practices on a regular basis. The dental students must be encouraged to be good role models in practicing as well as promoting oral health for their patients, families, friends and ultimately the society. The authors would like to recommend incorporating some oral health and preventive dentistry topics in the non-clinical BDS curriculum.

\section{ACKNOWLEDGEMENTS}

We would like to acknowledge the BDS students of Kantipur Dental College for their enthusiastic participation.

\section{REFERENCES}

1. Al-Zarea BK. Oral Health Knowledge of Periodontal Disease among University Students. Int J Dent. 2013;2013:647397.

2. Rajkarnikar J, Acharya J. Prevalence and severity of periodontal diseases among Nepalese adults - a hospital based study. J Coll Med Sci Nepal. 2014;10(1):11-6.

3. Newman MG, Takei HH, Klokkevold PR, Carranza FA, editors. Carranza's Clinical Periodontology - A South Asia Edition. 11th ed. New Delhi, India: Saunders, Elsevier; 2011.

4. AlJehani YA. Risk factors of periodontal disease: review of the literature. Int J Dent. 2014;2014:182513.

5. Williams RC. Understanding and managing periodontal diseases: a notable past, a promising future. J Periodontol. 2008 Aug;79(8 Suppl):1552-9.

6. Mehrotra V, Garg K, Sharma P, Sajid Z, Singh R (2015) A Study Based on Dental Awareness, Knowledge and Attitudes among the Medical Practitioners in and Around Kanpur City (India). J Interdiscipl Med Dent Sci. 2015;3:183.

7. Andhare MG, Dhonge RP, Dhuldhwaj RM, Dede RA Sayyad IFN. A comparative evaluation of awareness regarding periodontal health and oral hygiene practices among dental and medical undergraduate students in Beed District of Maharashtra. Indian J Dent Sci. 2017;9:215-9.

8. Ahamed S, Moyin S, Punathil S, Patil NA, Kale VT, Pawar G. Evaluation of the Oral Health Knowledge, Attitude and Behavior of the Preclinical and Clinical Dental Students. J Int Oral Health. 2015;7(6):65-70.

9. Sharda AJ, Shetty S. A comparative study of oral health knowledge, attitude and behaviour of first and final year dental students of Udaipur city, Rajasthan, India. Int J Dent Hyg. 2008 Nov;6(4):347-53.

10. Al-Omari QD, Hamasha AA. Gender-specific oral health attitudes and behavior among dental students in Jordan. J Contemp Dent Pract. 2005 Feb;6(1):107-14. 